\title{
Tratamento de fitiríase palpebral com ivermectina
}

\author{
Treatmentofphthiriasis palpebrarum with ivermectin
}

\author{
José Byron Vicente Dias Fernandes ${ }^{1}$ \\ Paulo Gelman Vaider Gorn ${ }^{2}$ \\ Suzana Matayoshi ${ }^{3}$
}

${ }^{1}$ Médico Colaborador da Clínica Oftalmológica do Hospital das Clínicas da Universidade de São Paulo.

2 Médico Pós graduando da Clínica Oftalmológica do Hospital das Clínicas da Universidade de São Paulo. ${ }^{3}$ Médica Assistente-doutora da Clínica Oftalmológica do Hospital das Clínicas da Universidade de São Paulo. Nenhum dos autores possui interesse comercial em qualquer produto citado neste estudo.

Endereço para correspondência: Clínica Oftalmológica do Hospital das Clínicas da Universidade de São Paulo - Av. Dr. Eneas Carvalho de Aguiar, 255 $6^{\circ}$ andar - Sala 6147 - CEP 05403-000.

\section{RESUMO}

Os autores descrevem um caso de paciente de 16 anos portadora de fitiríase palpebral tratada com ivermectina por via oral. Embora esta droga já esteja em uso há vários anos para terapêutica de outras parasitoses, ela também é reconhecidamente eficaz contra o Phthirus pubis. A maior vantagem de seu emprego na enfermidade aqui descrita pode residir na comodidade posológica.

Descritores: Infecções oculares parasitárias; Pestanas; Infestações por piolhos; Doenças palpebrais/quimioterapia; Ivermectina/uso terapêutico

\section{INTRODUÇÃO}

O Phthirus pubis, também conhecido como piolho pubiano ou chato, é um inseto hematófago e hospedeiro específico do ser humano ${ }^{(1)}$. É transmitido geralmente através de contato sexual, embora ocasionalmente também por roupas de uso pessoal, lençóis de cama e mesmo toalhas. A probabilidade de se adquirir uma pediculose pubiana após coito com alguém infestado é de aproximadamente $95 \%^{(1)}$. Seu ciclo de vida compreende cinco estágios: ovo, três fases de ninfa e o período adulto; o ovo é colocado dentro de um casulo que adere firmemente a um pêlo e que irá eclodir entre 5 a 10 dias, evoluindo então para a ninfa; esta emerge do casulo e deverá fazer uma refeição de sangue em no máximo 24 horas para não morrer ${ }^{(2)}$. Durante os 8 a 9 dias seguintes evoluirá em três estágios, atingindo então a fase adulta; aproximadamente 10 horas após atingí-la, macho e fêmea copulam, ato que continuará a acontecer até o fim de sua (curta) existência; nesse período o Phthirus requer freqüentes ingestões de sangue. A fêmea deposita ao redor de 4 ovos por dia até morrer. Todo o ciclo vital dura em torno de 1 mês. Embora o piolho pubiano habite preferencialmente a região da púbis, o fato de possuir garras serrilhadas permite-lhe transitar por todo o corpo humano ${ }^{(3)}$, explicando o seu aparecimento em setores distantes da área púbica num mesmo indivíduo, tais como axilas e mesmo cílios. Desta forma, fica fácil entender que a terapêutica à base de medicação tópica não logrará êxito completo a menos que seja aplicada a todas as áreas do corpo. De fato, muitas têm sido, ao longo do tempo, as formulações empregadas contra este mal; elas incluem malation a $0,5 \%{ }^{(4)}$ (que tem odor desagradável), lindano ${ }^{(5)}$ e piretrina ${ }^{(6)}$ (esta última extraída da planta crisântemo). Pomadas contendo óxido amarelo de mercúrio $^{(7)}$ e fisiostigmina ${ }^{(8)}$ tem sido utilizadas para as infestações ciliares. Recentemente, Buckhart e Buckhart relataram o emprego de Ivermectina administrada por via oral para o tratamento desta ectoparasitose ${ }^{(9)}$. Descrevemos a seguir a evolução de um caso em nosso meio tratado conforme essa nova (em oftalmologia) modalidade terapêutica. 


\section{DESCRIC̃̃̃ DE CASO}

Paciente do sexo feminino de 16 anos de idade compareceu com queixa de prurido e irritação palpebrais bilateralmente há 2 semanas. Ao exame apresentava algumas crostas junto às bordas palpebrais, bem como numerosos casulos e alguns piolhos aderidos à base dos cílios (Figura 1). Feito o diagnóstico de ftiríase, foi prescrito tratamento que consistiu de ivermectina por via oral (Revectina ${ }^{\circledR}$, Lab Sintofarma, $200 \mathrm{mg} / \mathrm{kg}$, ou seja, 2 compr. de $6 \mathrm{mg}$ cada: total $12 \mathrm{mg}$ em dose única). A paciente evoluiu com rápida melhora da sintomatologia local e ao retornar para novo exame após uma semana já não eram evidenciados os ectoparasitas junto aos cílios. As crostas haviam desaparecido e os casulos encontravam-se vazios (Figura 2). Foi-lhe então recomendado o uso de xampu neutro para limpeza dos cílios ao tomar banho. Por ocasião do retorno seguinte (após 7 dias), os cílios já se apresentavam livres de quaisquer casulos; na última consulta, após 21 dias, o quadro permanecia bom e a paciente recebeu alta.

\section{COMENTÁRIO}

A ivermectina é uma droga utilizada em medicina veterinária desde 1981. Seu emprego contra parasitoses humanas temse intensificado a partir da última década do século 20. Possui atividade farmacológica contra uma série de parasitas que inclui oncocercos, strongiloides, ancylostomas, sarcoptes,

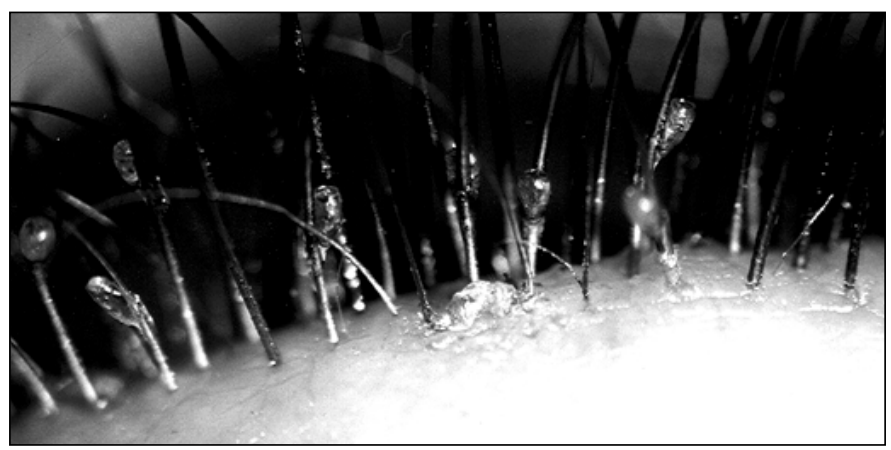

Figura 1 - Crostas, casulos, piolhos

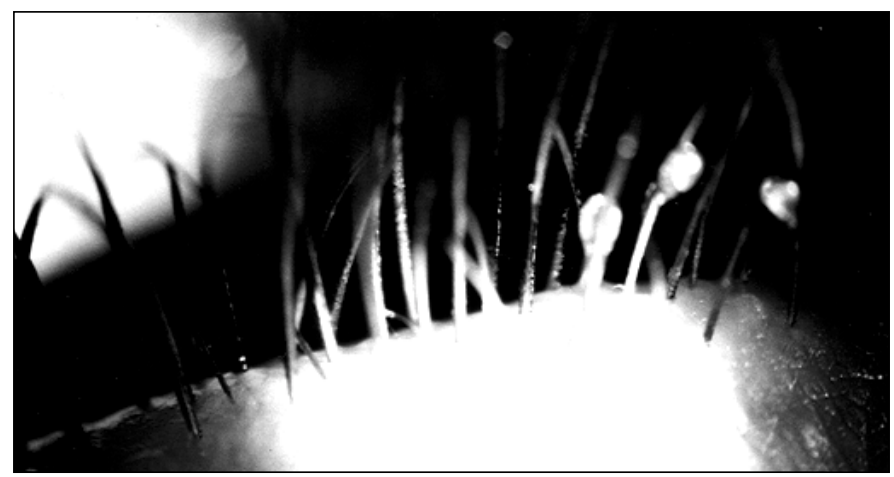

Figura 2 - Casulos vazios carrapatos e piolhos. Seu mecanismo de ação se baseia no bloqueio da transmissão sináptica que seja relacionada ao ácido gama amino butírico (GABA). Uma série de invertebrados que se utilizam desse neurotransmissor (tais como os piolhos) são portanto paralisados pela ação desta droga. Já os seres humanos (cuja transmissão neuromuscular não opera através do GABA) não são por ela afetados. A ivermectina tem uma meia-vida de $16 \mathrm{~h}$, de modo que apenas uma dose poderá não ser suficiente para controlar a fitiríase; isto se deve ao fato de que embora os níveis séricos do medicamento sejam suficientes para matar os parasitas já adultos (que fazem várias refeições de sangue ao longo do dia), a possibilidade da eclosão de novas ninfas nos dias seguintes obriga muitas vezes à administração de uma $2^{\underline{a}}$ dose após 7 dias. Na paciente do caso em questão isto não foi necessário pela absoluta ausência de parasitas na ocasião de seu retorno, porém aqui fica a ressalva. Vale relevar também a comodidade posológica desse modo terapêutico, já que com 2 comprimidos numa única ingestão eliminaram-se os parasitas. Na literatura esta droga é considerada segura, havendo já acima de 10 milhões de pacientes tratados para estrongiloidíase e oncocercose ${ }^{(10)}$; recomenda-se, no entanto, evitar o seu uso em crianças de menos de 3 anos de idade, bem como em gestantes e mulheres que estejam amamentando.

\section{ABSTRACT}

The authors report a case of a 16-year-old patient with phthiriasis palpebrarum treated with oral ivermectin. Although already used for a number of other parasitic diseases it is also effective against human lice. One outstanding advantage of that drug could be its easy medical regimen.

Keywords: Parasitic eye infections; Eyelashes; Ectoparasitic infestations; Eyelid diseases/drug therapy; Ivermectin/ therapeutic use

\section{REFERÊNCIAS}

1. Slonka GF. Life-cycle and biology of lice. J Sch Health 1977;47:349-51.

2. Burgess IF. Human lice and their management. Adv Parasitol 1995;36:271-42.

3. Ubelaker JE, Payne E, Allison VF, Moore DV. Scanning electron microscopy of the human public louse Phthirus pubis (Linnaeus, 1758). J Parasitol 1973;59:913-9.

4. Meinking TL, Taplin K, Kalter DC, Eberte MW. Comparative efficacy of treatments for pediculosis capitis infestations. Arch Dermatol 1986;122:267-71.

5. Sampaio SAP, Rivitti EA. Dermatozooses: dermatoses por hemípteros (barbeiros e percevejos). In: Sampaio SAP, Rivitti EA. Dermatologia. São Paulo: Artes Médicas; 1998. p. 580-1.

6. Burns DA. The treatment of human ectoparasite infection. Br J Dermatol, 1991;125:89-93.

7. Ashkenazi I, Desatnik HR, Abraham FA. Yellow mercuric oxide: a treatment of choice for phthiriasis palpebrarum. Br J Ophthalmol 1991;75:356-8.

8. Couch JM, Green WR, Hirst LW, de la Cruz. Diagnosing and treating Phthirus pubis palpebrarum. Surv Ophthalmol 1982;26:219-25.

9. Burkhart $\mathrm{CN}$, Burkhart CG. Oral ivermectin therapy for Phthiriasis palpebrum. Arch Ophtalmol 2000;118:134-5.

10. Meinkink T, Burkhart CG, Burkhart CN. Ectoparasitic diseases in dermatology reassessment scabies and pediculosis. Adv Dermatol 1999;15. 